
cultures

Les cahiers de l'Acedle

11-1 | 2014

Notions en questions - Corpus

\title{
How language learners can benefit from corpora, or not
}

\section{Ana Frankenberg-Garcia}

\section{OpenEdition}

\section{Journals}

Electronic version

URL: http://journals.openedition.org/rdlc/1702

DOI: $10.4000 /$ rdlc. 1702

ISSN: 1958-5772

\section{Publisher}

ACEDLE

Electronic reference

Ana Frankenberg-Garcia, « How language learners can benefit from corpora, or not », Recherches en didactique des lanques et des cultures [Online], 11-1 | 2014, Online since 07 January 2014, connection on 02 May 2019. URL : http://journals.openedition.org/rdlc/1702 ; DOI : 10.4000/rdlc.1702

This text was automatically generated on 2 May 2019.

\section{(c) $\mathbb{Q \Theta \Theta}$}

Recherches en didactique des langues et des cultures is licensed under a Creative Commons AttributionNonCommercial-NoDerivatives 4.0 International License 


\title{
How language learners can benefit from corpora, or not
}

\author{
Ana Frankenberg-Garcia
}

\section{Introduction}

1 Most people will have come into contact with corpus-based language aids developed by experts without even realizing that the tools and resources they are using were built thanks to corpora. That is the first way in which the general public can benefit from corpora. Next, language learners can come into contact with corpora when their teachers have received some kind of training in corpus linguistics and decide to prepare corpusbased materials for classroom use. And finally, with guidance from their teachers, language learners can also have a go at using corpora themselves. In this paper I will discuss these three ways in which corpora can be useful for language learners, drawing particular attention to the many ways in which corpora can be directly exploited by teachers and learners and to some of the common pitfalls that should be avoided.

\section{Published corpus-based tools and resources}

2 People are not generally aware that computational linguists use corpora to develop all sorts of language tools that have become commonplace in our everyday lives, from simple spell checkers, to auto-correct options in word processors and web browsers, to sophisticated machine translation programs. This is the first way in which learners can experience the benefits of corpora without realizing it. Likewise, people resorting to dictionaries may not know that a number of new-generation dictionaries have been compiled on the basis of corpus data. Lexicographers use corpora to find out how frequently words are used and then utilize this information to select which headwords are important to include in learners' dictionaries, which senses of polysemous words to present first, which words to use in the definitions, and which grammatical properties and collocations of words to draw attention to. Modern learners' dictionaries also 
complement basic information on senses with corpus-based examples that can help learners see how words are used in context, and with data from learner corpora in order to draw attention to certain aspects of language that can be particularly problematic. ${ }^{1}$

Apart from dictionaries, at least in the ELT (English language teaching) market, there is a growing body of grammars and textbooks with pedagogical explanations and exercises that draw on corpus data ${ }^{2}$. Figure 1 lists a few corpus-based dictionaries, grammars and textbooks for learners of English.

Figure 1 - Examples of corpus-based ELT publications

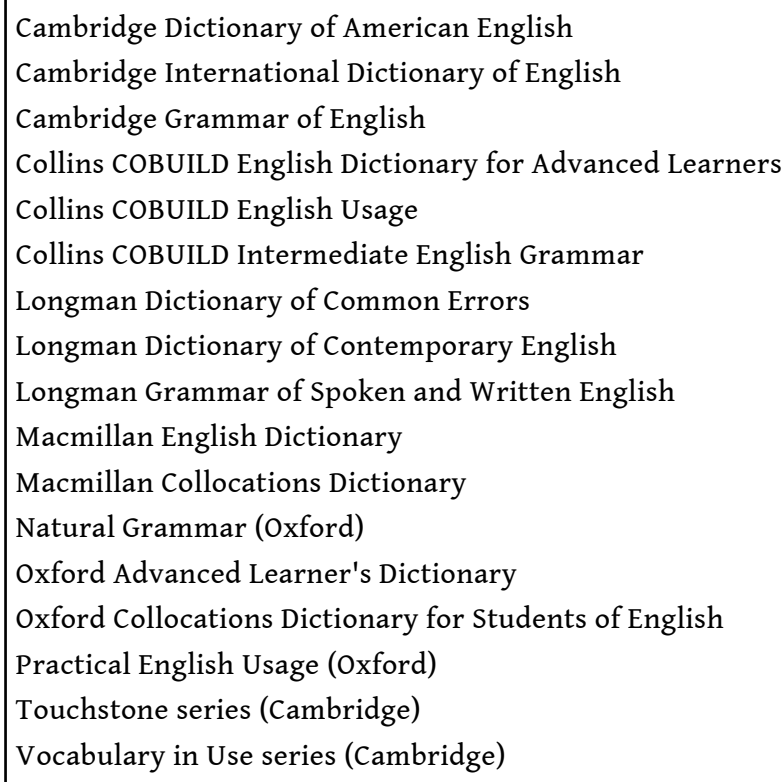

4 Materials like the ones outlined in Figure 1 contain language that has been selected and edited by experts, so its users are not required to understand what a corpus is or to have direct contact with corpora. In the first book of the Touchtone series (McCarthy et al., 2005), for example, students get titbits of corpus information right from the start: in conversation, "phone is six times more common than telephone" (p. 6); "yeah is ten times more common than yes" (p. 9); "people use 's not and 're not after pronouns [...] Isn't and aren't often follow nouns" (p. 25); "people say Sometimes I seven times more often than I sometimes" (p.46); and so on. On the one hand, this is excellent, since a lot of the information that can be extracted from raw corpus data has already been processed by experienced professionals, which means teachers and learners can benefit from the final product without having to worry about how it was obtained. On the other hand, the amount of language that can be presented in this polished format is limited, simply because language is infinitely bigger and more complex than what can be summarized in a book or any other language learning aid. Language learners (and their teachers) often have questions for which there are no answers or which are not treated in sufficient detail in dictionaries, grammar books and other publications. Corpora can provide more language, and can disclose solutions to language queries that have not been dealt with in edited linguistic resources. This is why another option is for teachers and learners to use corpora directly, as shall be seen below. 


\section{Direct uses of corpora}

5 When Tim Johns and his students at the University of Birmingham began exploring corpora directly in one-to-one student-teacher consultations in the late 1980s, in an approach that came to be known as 'data-driven learning' (Johns, 1991), the use of computers was not widespread and corpora were not accessible to the general public. More than twenty years have gone by, and nowadays there are a number of corpora in various languages that can be easily accessed online by anyone with a connection to the internet. It is no longer necessary to be a linguist, a lexicographer or any other kind of language expert working at a research centre or for a commercial publisher to be able to access a corpus. Although according to Mukherjee (2004) and Frankenberg-Garcia (2012a), not many language teachers, let alone learners, will have heard of corpora, at least in Britain there now seem to be a number of MA degrees in ELT that include modules or module components about corpora. There are also books about using corpora in the classroom (e.g. Reppen, 2010; Bennett, 2010), and several online tutorials too. ${ }^{3}$

Language teachers who have received some training in corpus linguistics can resort to corpora to complement their teaching in all sorts of ways. This means learners can come into contact with corpora indirectly, by means of corpus-based materials and activities prepared by their teacher, or directly, when they are prompted by their teacher to use corpora themselves. Gabrielatos (2005) has referred to this as the 'soft' and the 'hard' approaches to corpus use respectively, while Boulton (2010a) termed this same distinction the 'hands-off' and 'hands-on' approaches. In this paper I shall refer to the latter, simply because it is more mnemonic. As observed in Frankenberg-Garcia (2012b), the hands-off and the hands-on approaches are not mutually exclusive, and I hope it will become clear in this paper that there is a time and place for both.

\subsection{Using corpora hands-off}

When resorting to corpora hands-off, learners do not need to learn how to use concordancing software, and as pointed out by Boulton (2010a), this can be a great advantage, since learners may find it difficult to understand how to work with the software and may not know what exactly to do with corpora or how to interpret the results they get. There are countless different types of hands-off corpus-based materials and activities that teachers can prepare for their students, but it is crucial that teachers are able to use them judiciously.

8 The mere fact that a handout or a classroom activity is based on corpora is no guarantee of quality or success. Let me give an example. Imagine you are learning English and your teacher has given you a printout with the concordance lines in Figure 2, and asked you to try and discover what grimple means. By reading them, you can deduce that grimple is a noun, that people wear grimples (probably on their heads) and that a grimple can hide your face. Putting it all together, you can get a vague idea of what grimple might mean, but maybe you are not $100 \%$ sure.

9 From a purely linguistic perspective, or from the viewpoint of language awareness, this is a very interesting exercise, as it helps learners to realize that meaning can be derived from context. But why would learners bother with exercises such as this one, when it would have been far simpler and a lot faster to look up the word in a dictionary? In the 
present case, the concordance lines for grimple are in actual fact concordance lines for helmet. According to the Macmillan English Dictionary Online, a helmet is a hard hat that you wear to protect your head, and according to the English-French dictionary at Oxford Dictionaries Online, a helmet is a casque. If you did not know the meaning of helmet, it would have been a lot quicker to find out what it meant by looking it up in a dictionary instead of being asked to analyse corpus data like a trained lexicographer or linguist. Learners may very well perceive it is a waste of time and effort to spend so much time analysing concordances when they can find out what words mean more efficiently and effectively using a dictionary. Indeed, this kind of corpus-based exercise can be downright frustrating, especially if learners only have a few hours a week to study a language.

Figure 2 - Random concordance lines for grimple ${ }^{4}$ from $\operatorname{COCA}^{5}$

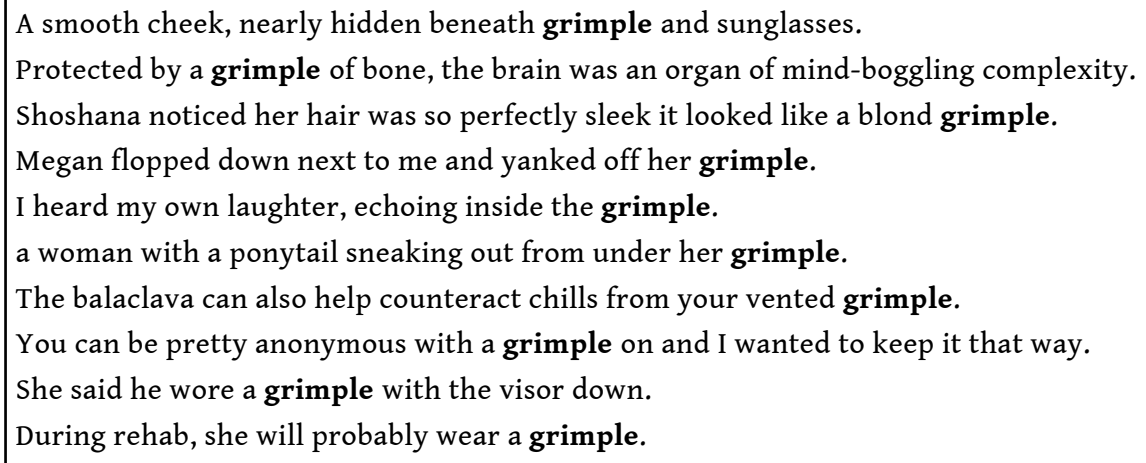

10 A very different situation is to use concordances to reinforce the meaning of words that learners have heard for the first time in class or elsewhere, and to which they have not had the opportunity to be exposed more fully. In Frankenberg-Garcia (2012b), I gave the example of learners not understanding the meaning of the word aisle, which they had encountered for the first time in a dialogue in their coursebooks. The word appeared in the context of air travel, and its meaning in that sense was briefly explained immediately after the learners had asked what it meant. In the following lesson, the learners were then given the hands-off exercise in Figure 3. Although the concordance used in the aisle exercise are essentially similar to the ones used in the grimple exercise in that they both focus on a given word and draw attention to the contexts in which that word is used, the two exercises are in actual fact very different. Rather than focusing on a random word selected by the teacher, the concordance lines for aisle focus on a word that the learners were already curious about because they had not understood it when it was presented to them in an authentic classroom situation. Rather than asking the learners to use concordances to figure out the meaning of a word at random as if they were linguists or lexicographers, the concordance for aisle was used to expand the learners' previous oneoff contact with the word in the classroom. With the aisle exercise, the learners' exposure to the new input was exponentially enhanced with concentrated doses of the word in context. The concordance also enabled the learners to figure out that aisles exist not just on aeroplanes, which was the original context in which they had seen the word, but also in places like trains, shops, churches and supermarkets. Additionally, the concordance served to help the learners notice that there is a distinction between aisles and corridors which does not exist in the learners' native Portuguese. 
Figure 3 - Handout with selected BNC ${ }^{6}$ concordance lines for aisle (Frankenberg-Garcia, 2012b: 40)

A. Read the sentences below and make a list of the sort of place where aisles are found.

\section{B. Does aisle translate into Portuguese always in the same way?}

1. The air hostesses inquired what I was making and a man passing in the aisle quite genuinely complimented me on my work.

2. I arrived at Salisbury Cathedral, just as the bride was about to go up the aisle.

3. As she looked around she felt a twinge of sadness that in a carriage where 70 per cent of the commuters were men there were five women forced to stand in the aisle.

4. They looked at the passports and then started to walk down the aisle, pointing their guns at the passengers.

5. He hurried up the aisle of the church.

6. She picked up her suitcase and made her way along the aisle.

7. The layout of the store, with wide aisles, gives customers room to move around.

8. I spend much of my time at the shops; wandering through the aisles, faltering, never knowing what to buy.

11 In addition to enhancing language comprehension, concordances can also be very useful in language production. Sometimes learners already know the meanings of words but have problems using them correctly. Concordances illustrating how words are used in context can help learners overcome these difficulties. For example, a frequent error by Portuguese learners of English is to say *congratulations for something. Figure 4 shows how a handout with concordance lines for congratulations can help these learners notice what prepositions to use after congratulations.

FIgURE 4 - Handout with selected concordance lines from enTenTen ${ }^{7}$ for congratulations.

\begin{tabular}{|l|}
\hline A. Underline the prepositions used after congratulations \\
\hline B. What sorts of things come after each preposition? \\
\hline Our congratulations to all the candidates and to the winners. \\
\hline Congratulations on a job well done. \\
\hline Congratulations from us all. \\
\hline Congratulations on your impending marriage! \\
\hline I do not expect congratulations from you. \\
\hline
\end{tabular}




\begin{tabular}{|l|}
\hline Congratulations on your 100th birthday! \\
\hline Congratulations on your decision. \\
\hline Congratulations to whoever made that call! \\
\hline Congratulations to the artist. \\
\hline So congratulations to all the authors. \\
\hline We got lots of congratulations from passers-by \\
\hline
\end{tabular}

Concordance-based activities can also help learners expand their vocabulary and use the target language more idiomatically. As exemplified in Figure 5, Frankenberg-Garcia (2012b) suggests an activity with a concordance for the bus, used to help learners employ more idiomatic English when writing a composition about something that happened on a bus.

Figure 5 - Handout with selected BNC and COCA concordance lines for the bus (FrankenbergGarcia 2012b:43)

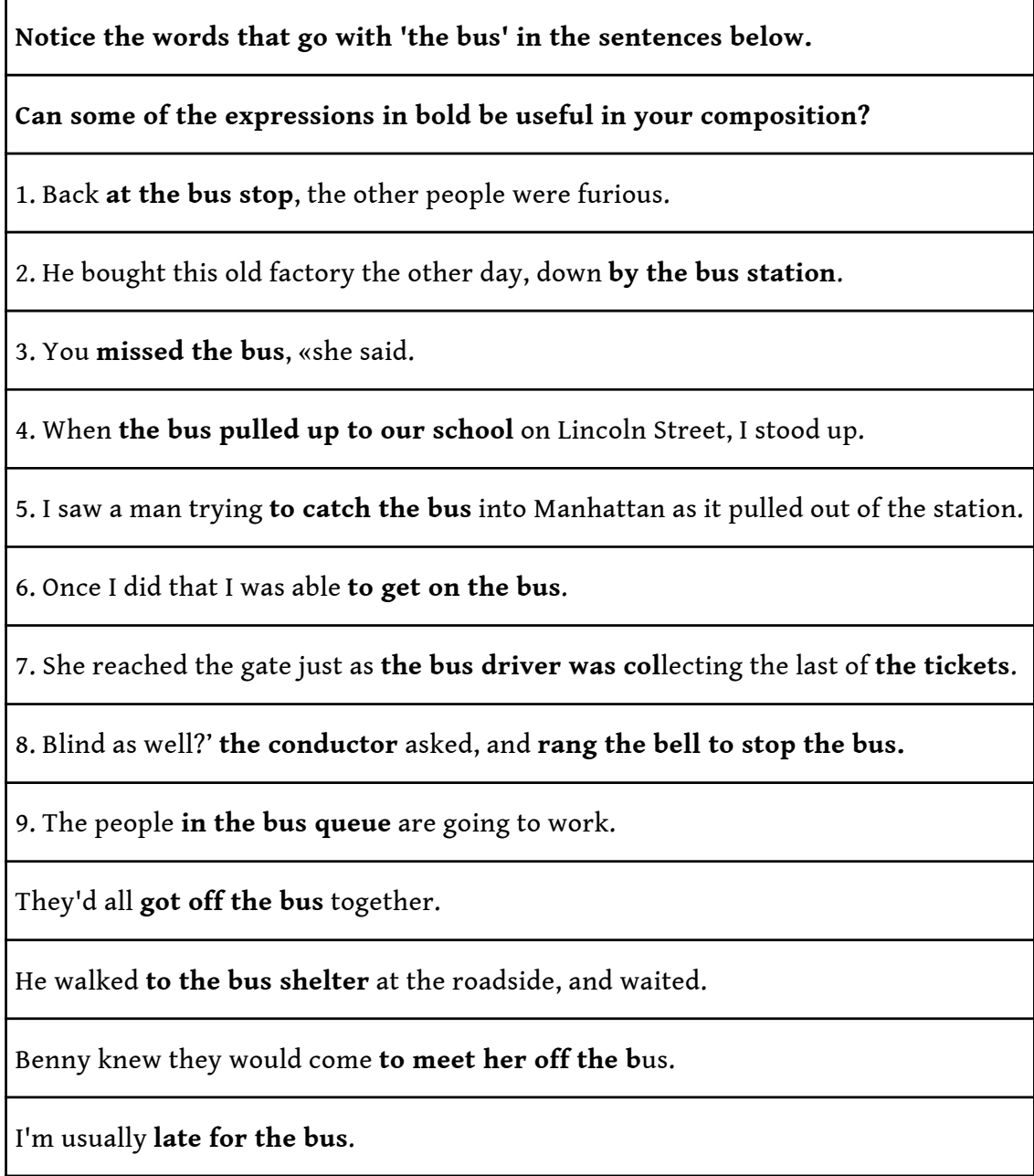


I always miss the bus.'

I used to ride the bus by myself when I was your age.

Hands-off activities need not be endless lines of concordances printed on paper. When concordances are presented to groups of students in slide format, it is easier for the whole class to discuss them together. Figure 6 shows a screenshot of a concordance-based slide presentation devised to help learners understand which prepositions to use after pay. It was developed to complement a unit about payment methods in the regular textbook adopted in class, as a reaction to the observation that the students were making many errors regarding the use of the prepositions in the context of pay. In the first few slides, the learners were led to figure out the differences between paying people (no preposition), paying for things in general, paying bills/taxes/rents/etc. (no preposition), paying in different currencies and cash, and paying by cheque/credit card/etc. In the excerpt shown, the learners practised using the appropriate prepositions in a conventional gap-fill exercise. What was different, however, was that instead of the bland content that is usually given in traditional exercises for practising grammar, the concordance lines used (extracted from COCA) prompted the students to discuss all sorts of issues related to them, such as why Americans living in Europe and being paid in dollars feel like they have taken a pay cut (line 1), why someone in Russia would get paid in dollars (line 3), and whether they were paid to do odd jobs at home when they were little (line 10). Thus in addition to being exposed to massive doses of the word pay in context, the students also had stimulating conversation topics to discuss as a group, in what may have otherwise been just another solitary and boring grammar practice exercise.

Figure 6 - Excerpt of classroom slides with a concordance-based exercise to practise the prepositions used after pay ${ }^{8}$.
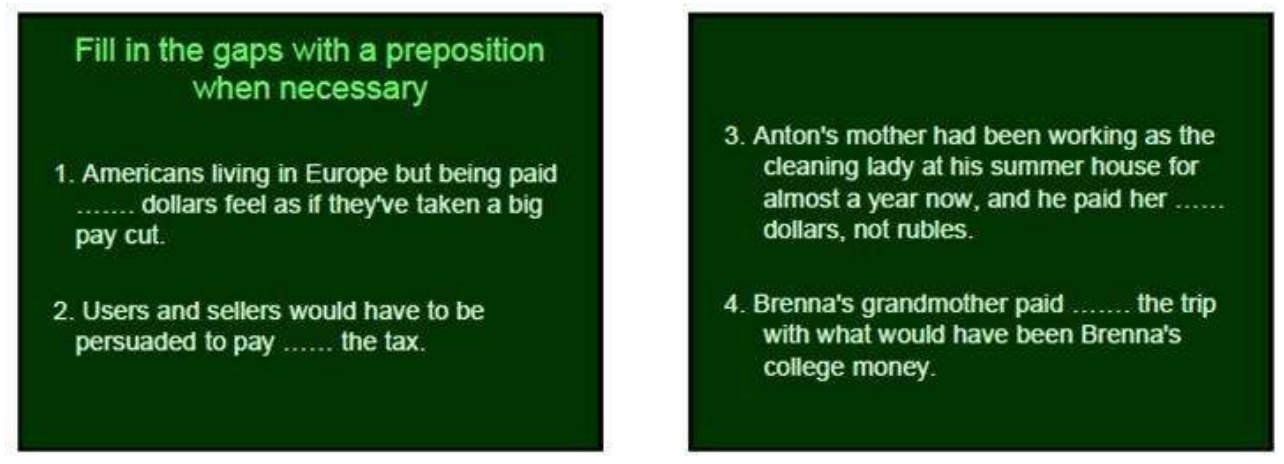

Another way of working with hands-off concordances without paper is to transpose them to interactive electronic exercises for the web. With the help of user-friendly freeware like HotPotatoes 9 , teachers can prepare concordance-based interactive exercises which learners can then work on at their own pace. Figure 7, taken from Frankenberg-Garcia (2012b), shows a screenshot of a computer-assisted language learning (CALL) exercise with a concordance from COCA used to help Portuguese learners of English for Tourism become more familiar with non-metric units of measure used in the USA. In this exercise, the students choose from a dropdown list of options words like feet, inches, gallons, ounces, wide, long, high, weigh and so on to fill in the gapped concordance lines. 
Figure 7 - Non-metric units, concordance-based CALL exercise (Frankenberg-Garcia (2012b:42) ${ }^{10}$

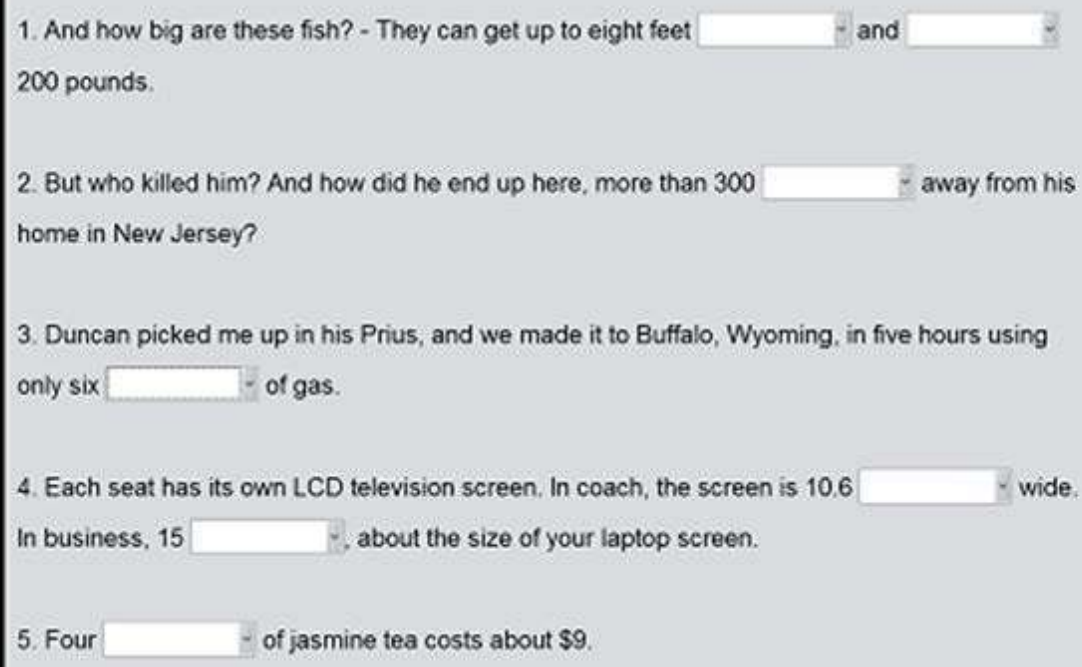

15 Although concordance-based exercises like the ones outlined above can be very stimulating, it is important to bear in mind that the learners using them will not have received any training in corpus linguistics. Note that in all concordance-based activities exemplified so far, not once was the word 'concordance' mentioned. There is no reason why teachers should confuse learners with corpus-linguistics terminology when it is perfectly possible to give instructions using general words like sentence or sentence extract instead of concordance.

It is important to stress here that it is not enough to present learners with concordance lines and tell them vaguely to 'notice things'. Learners should receive very specific guidelines on what to look out for in the concordances or they will probably not understand what the purpose of the exercise is. In the examples given, learners are guided along what they are supposed to do with the data and are led to interpreting it in the ways the teacher had planned them to interpret it. Although language is not black and white and it is not possible to predict all that is going happen (i.e. learners will also notice things which the teacher had not anticipated), the point I want to make here is that learners will at least have been told exactly what to observe and that the essential aspect of language that the teacher had intended to present will have been covered.

Another recommendation is for teachers to select which concordance lines they want to transpose to a handout rather than printing them out indiscriminately. There is no harm in editing the concordances presented to learners so as to correct languages mistakes ${ }^{11}$, leave out language that is considered too difficult for the level of proficiency of the learners, exclude language that is offensive or sensitive or for any other reason inappropriate for classroom use, or simply omit items which aren't obviously relevant to the senses or uses being targeted. Although we wouldn't want to do this if we were using corpora for purely linguistic analysis where data about language mistakes, offensive senses, and so on are all relevant, from a pedagogical standpoint we do not need to swamp language learners with raw corpus data. The possibility of sheltering learners from many of the problems of dealing with raw corpus data is in fact an added advantage of presenting learners with hands-off concordances. 
Having said this, a learner's hands-off contact with corpora need not be based on concordances alone. As demonstrated in Frankenberg-Garcia (2012b), collocation data can be used to boost vocabulary related to practically any topic. Figure 8 , for example, shows a word sketch (i.e. a one-page, automatic corpus-based account of a word's grammatical and collocational behaviour generated by Sketch Engine; Kilgarriff et al., 2004) for the noun guitar in the enTenTen corpus (Jakubíček et al., 2013). A teacher can instantly select from this screenshot words that learners might want to use when talking about guitars, such as what people can do with guitars (strum, play, tune, etc.), what types of guitars there are ( acoustic, electric, bass, classical, etc.), what sort of nouns can be modified by guitar (riff, solo, chord, etc.), and so on. These can be presented to learners in a brainstorming session or in any other format.

Figure 8 - A word sketch for guitar ${ }^{12}$

\begin{tabular}{|c|c|c|c|c|c|c|c|c|c|c|c|c|c|c|c|c|}
\hline \multicolumn{17}{|c|}{ sultar (noun) } \\
\hline object of & 113493 & 0.3 & subject of 52 & 21890 & 0.2 & & ij subject of & 7089 & 0.2 & modifier & 183252 & 0.2 & \multicolumn{2}{|c|}{ modifies 1} & 183390 & 0.2 \\
\hline strum & 1504 & 8.59 & strum & 6298 & 8.28 & & ft-handed & 23 & 5.15 & acoustic & 19677 & 711.04 & \multicolumn{2}{|c|}{ riff } & 5001 & 9.3 \\
\hline play & $\underline{36699}$ & 7.38 & solo & 4057 & 7.83 & & strumental & 80 & 3.99 & electric & 16954 & 9.42 & \multicolumn{2}{|c|}{ solo } & 7519 & 9.07 \\
\hline tune & 1722 & 7.34 & riff & 3117 & 7.46 & & oustic & 59 & 3.89 & bass & 8148 & 8.85 & \multicolumn{2}{|c|}{ chord } & 4438 & 8.61 \\
\hline pedal & 350 & 5.95 & pedal & $\underline{265} 6$ & 6.12 & & ripheral & 29 & 3.54 & classical & 3701 & 8.21 & \multicolumn{2}{|c|}{ playing } & 4531 & 8.21 \\
\hline chime & 204 & 5.57 & shred & 965 & 5.29 & & miniscent & 28 & 3.18 & lead & 2989 & 7.82 & \multicolumn{2}{|c|}{ amp } & 2359 & 7.88 \\
\hline harp & 198 & 5.57 & tune & 3165 & 5.17 & lou & & 81 & 3.18 & rhythm & 2355 & 7.27 & \multicolumn{2}{|c|}{ bass } & 3394 & 7.59 \\
\hline jangle & 141 & 5.29 & sound & 11635 & 5.09 & & ominent & 38 & 1.92 & Fender & $\underline{763}$ & 6.97 & \multicolumn{2}{|l|}{ lick } & 1269 & 7.53 \\
\hline master & $\underline{387}$ & 5.29 & wail & 724 & 4.93 & & rsatile & 20 & 1.67 & distorted & $\underline{816}$ & 6.95 & \multicolumn{2}{|c|}{ string } & 4510 & 7.38 \\
\hline plug & 321 & 5.18 & jangle & 514 & 4.89 & ont & tine & 486 & 1.11 & -string & 692 & 6.93 & \multicolumn{2}{|c|}{ lesson } & 7484 & 7.33 \\
\hline wail & 151 & 5.16 & fret & 79.4 & 4.71 & & & & & vocal & $\underline{1465}$ & 6.87 & \multicolumn{2}{|c|}{ neck } & 3808 & 6.95 \\
\hline pluck & 169 & 5.1 & hook & $\underline{191} 4$ & 4.64 & & & & & beginner & 1556 & 6.87 & \multicolumn{2}{|c|}{ drum } & 1288 & 6.86 \\
\hline smash & 219 & 5.07 & pluck & 614 & 4.31 & & & & & Gibson & 986 & 6.72 & \multicolumn{2}{|c|}{ tab } & 2150 & 6.81 \\
\hline and/or & 99710 & 0.2 & PP_obj of - i & 2539 & 1930. & .2 & pp_obi_on-i & 20627 & 70.6 & \multicolumn{2}{|c|}{ pp_obi_with-i } & 10786 & 0.3 & $p p$ in $-i$ & i 6910 & 0.1 \\
\hline vocal & 6987 & 9.46 & strum & & 187. & .27 & strum & 157 & $7 \quad 7.2$ & arm & & 153 & 4.98 & band & 552 & $=2.93$ \\
\hline drum & 4960 & 9.18 & neck & 333 & 3377. & .01 & chord & 336 & 65.72 & ballad & & 28 & 3.48 & lap & 60 & 02.62 \\
\hline bass & 7567 & 8.97 & headstock & & 435. & .57 & wail & 61 & 15.46 & experime & nent & 28 & 2.95 & tune & 84 & $4 \quad 2.54$ \\
\hline mandolin & 1538 & 8.71 & twang & & 475. & .51 & strap & 124 & $4 \quad 5.39$ & vocal & & 41 & 2.5 & hand & 544 & 41.29 \\
\hline banjo & 1616 & 8.61 & playability & & 375. & .15 & fret & 59 & 9. 4.84 & solo & & 49 & 2.49 & studio & 52 & $2 \quad 1.01$ \\
\hline piano & 4928 & 8.59 & fretboard & & 33. & 91 & lick & $\underline{52}$ & 24.76 & synonym & nous & 18 & 2.42 & & & \\
\hline harmonica & 945 & 8.04 & fret & & 454. & .35 & improvise & 51 & 14.75 & melody & & 30 & 2.28 & & & \\
\hline violin & 1486 & 7.95 & accompaniment & & 534. & .32 & jamming & 37 & 74.72 & amp & & 22 & 2.21 & & & \\
\hline pereussion & 1035 & 7.73 & string & & 4314 & .27 & riff & & 24.6 & dude & & 28 & 2.16 & & & \\
\hline keyboard & 3336 & 7.54 & mastery & & 614. & .13 & Clapton & $\underline{27}$ & 7.48 & stool & & 19 & 1.71 & & & \\
\hline fiddle & 770 & 7.43 & fret & & 254. & .04 & shred & 33 & 34.46 & pair & & $\underline{18}$ & \multirow{2}{*}{1.69} & & & \\
\hline flute & 941 & 7.41 & Neck & & 274. & .01 & strino & 450 & 0. 4.34 & $\sin \theta$ & & 62 & & & & \\
\hline
\end{tabular}

\subsection{Using corpora hands-on}

In addition to using ready-made corpus-based materials and to teachers preparing handsoff activities and materials suitable for their particular groups of learners, the third way in which learners can come into contact with corpora is hands-on. This has often been reported as being more problematic than using corpora hands-off (for example, see Gabrielatos, 2005; Boulton, 2010a), for in addition to computers being needed in the classroom, learners will also have to grapple with new technology, raw corpus data and a new approach to learning, all at the same time. From a technological viewpoint, language classrooms are not usually equipped with computers, language learners may not be technology lovers, computers can crash, the online connection can fail, and concordancing software does not tend to be particularly user-friendly. From the perspective of the corpus itself, learners have to decide what corpus to use, understand 
the strengths and limitations of the chosen corpus, and interpret the results they get in the light of the first two of these factors. And from the viewpoint of learning, learners may feel overburdened with having to decide what aspect of language to explore, with having to read unedited text, and with not knowing what to look out for when scrolling down countless lines of concordances.

As if all this were not enough to completely discourage the hands-on use of corpora by language learners, another problem is that many of the hands-on activities proposed in the literature encourage learners to use corpora as if they were linguists. Textbooks about using corpora with language learners are full of ideas for hands-on activities that can be carried out in the classroom; but while interesting from the viewpoint of language research, many of the suggestions given tend to be dissociated from the reality of everyday language learning. Reppen (2010: 44), for example, suggests that learners can look up in Micase ${ }^{13}$ which texts "have the highest normed counts for well and then go to those texts and see if well is being used as a filler [...], as a discourse marker [...] or as an adverb". Another activity proposed by Reppen (2010: 62) is to ask learners to create frequency lists for newspaper texts and scan the resulting word lists for difficult items in order to determine the level of difficulty of each text. Exercises such as these can be interesting for a linguist, but I would argue that a language learner simply wants to be able to use the language rather than analyse it. Why would a language learner need to know what 'fillers' and 'discourse markers' are? Why would they need to establish the level of difficulty of texts? In the same way that the hands-off grimple exercise described earlier is relevant to the linguist and the lexicographer but not necessarily to the language learner, hands-on exercises too must focus on the interests and needs of learners rather than on linguistic analyses that are not immediately applicable to language learning.

21 As I argued in Frankenberg-Garcia (2012b), hands-on corpus consultation seems to be particularly suited to answering individual questions learners have and which emerge when they are writing or when they are receiving feedback to their writing, such as 'how do you say this?', 'is this right?', 'which word sounds better, this or that?', 'what verb/ adjective/preposition/etc. should I use here?', 'why is this wrong?', and so on. If all learners are asking the same questions, then it might be worth preparing hands-off activities for the group as a whole. However, there will be many questions that are not relevant to the entire class, but only to individual learners. This is when it might be useful to teach learners to use corpora to look up the answers they need by themselves. Of course, if the answers can be found more readily in dictionaries, learners should use dictionaries first for the simple reason that it will be quicker, as noted earlier in the grimple example. However, not even the best learners' dictionaries will have the answers to all the questions that emerge when a person is learning a new language.

Learners do not need to be taught what corpora are or to be trained to carry out linguistic analyses as if they were linguists. All that is really necessary is to show learners how to look up the answers to their specific questions. In Frankenberg-Garcia (2012b: 42) I gave the example of a learner wanting to know which preposition to use in the context of $I$ received a message _- my cell phone. As the information provided in a learners' dictionary was not enough, the teacher demonstrated how the learner could look up a concordance for cell phone in the context of message in COCA so as to retrieve the concordance lines in Figure 9 , from which it became instantly clear to the learner which preposition to use. 
Figure 9 - Concordance for cell phone in the context of message in COCA (Frankenberg-Garcia, 2012a: 42)

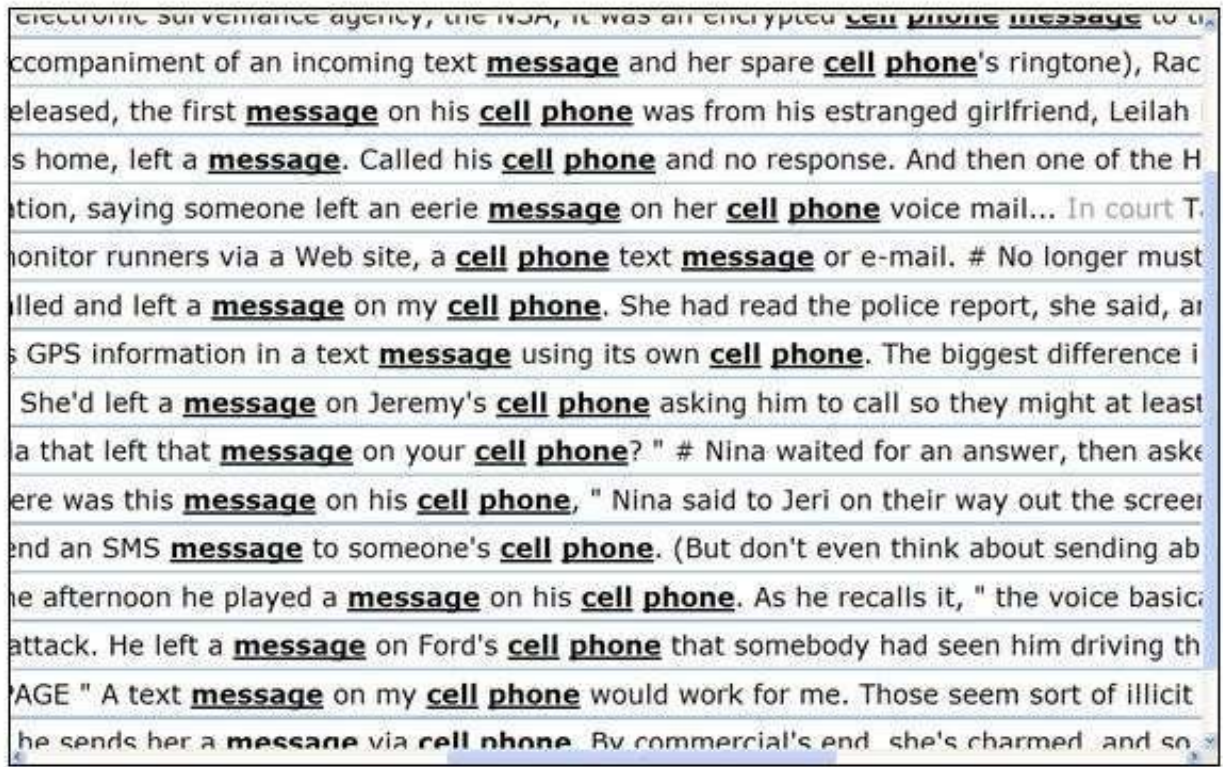

In another situation, during a session where learners were looking at different ways of ending business letters, one of the students questioned the use of I look forward to hearing from you. She said her former tutor (a native speaker of English) had told her that the right way of saying this was using the present continuous: I am looking forward to hearing from you. In the present case, the teacher (a non-native speaker) felt both forms were correct, but for reassurance she showed the student how to look up the strings look forward to hearing/seeing and looking forward to hearing/seeing in the Business Letter Corpus ${ }^{14}$, which contains around 1 million words of sample UK and US business letters. The results summarized in Figure 10 showed both the student and the teacher that not only was it perfectly acceptable to end a letter with look forward to hearing/seeing, but also that it seemed in fact to be more conventional than looking forward to hearing/seeing.

Figure 10 - Distribution of looking/look forward to seeing/hearing in the Business Letter Corpus

\begin{tabular}{|l|l|}
\hline Search string & Corpus Frequency \\
\hline look forward to hearing & 212 \\
\hline looking forward to hearing & 19 \\
\hline look forward to seeing & 156 \\
\hline looking forward to seeing & 15 \\
\hline
\end{tabular}

Demonstrating to learners that they can use 'this online tool' (there is no need to say it is a corpus) 'like this' (showing how to carry out the relevant query) to find out answers to questions about language that are in the forefront of their minds can help them see the utility of corpora immediately. If students are not all asking questions at the same time, a 
single computer in class used like a shared dictionary will often suffice. Little by little, with more questions and more demonstrations on how corpora can help to fulfil their language needs, some learners may begin to use corpora autonomously, without the teacher's support. It is unlikely that they will ever become power users of corpora capable of carrying out sophisticated queries and analyses, but I do not think this is what the average language learner aims for. It will already be a great achievement if learners manage to use corpora hands-on to answer their own immediate questions about language.

\section{Conclusion}

I hope to have shown that learners can benefit from corpora in three ways: via published corpus-based language learning resources developed by experts for the general public, via tailor-made hands-off exercises and activities prepared by their teachers, and via hands-on queries they carry out themselves. I also hope to have made it clear that there is a time and place for each way of using corpora, and that the fact that a resource or activity is corpus-based does not automatically mean that it is 'good'. In particular, there are numerous hands-off exercises and activities that can be created, but when preparing them teachers must make sure that they are relevant, useful and accessible to their particular group of learners. Likewise, there are hundreds of ways in which learners can explore corpora hands-on, but it is easy for learners not to know what queries to carry out or what to do with the data retrieved. Most importantly, learners cannot be expected to be captivated by analysing corpus data, just because it is fascinating to linguists and language teachers. Unfortunately, quite a few of the corpus activities for language learning exemplified in the literature have more to do with the linguist's interest in language than with language learners' actual needs. But if teachers bring to the classroom corpus-based materials and activities conceived to complement the regular materials adopted in class, that will help learners develop their language skills more fully, and if learners are taught how corpora can be used hands-on to help them find the specific information about language that they cannot find elsewhere, then I believe the direct use of corpora by language learners can be made to work. To conclude, I should like to point out that when examining different studies about learners' reactions to data-driven learning ${ }^{15}$, one should be extra careful when comparing one study with another for the simple reason that there many different ways in which data-driven learning can be implemented in the classroom, some being much better than others, depending on local contexts and needs.

\section{BIBLIOGRAPHY}

Bennett, G. (2010). Using corpora in the language learning classroom : corpus linguistics for teachers. Michigan : University of Michigan Press. 
Boulton, A. (2010a). "Data-driven learning : taking the computer out of the equation". Language Learning, vol. 60, $\mathrm{n}^{\circ}$ 3. pp. 534-572.

Boulton, A. (2010b). "Learning outcomes from corpus consultation". In Moreno Jaén, M., Serrano Valverde, F. \& Calzada Pérez, M. (dir.), Exploring new paths in language pedagogy : lexis and corpusbased language teaching. Londres : Equinox. pp. 129-144.

Davies, M. (2008). The Corpus of Contemporary American English (COCA) : 410+ Million Words, 1990Present. Available on line. http://www.americancorpus.org

Frankenberg-Garcia, A. (2012a). "Raising teacher's awareness of corpora". Language Teaching, vol. $45, n^{\circ} 4$. pp. $475-489$.

Frankenberg-Garcia, A. (2012b). "Integrating corpora with everyday language teaching". In Thomas, J. \& Boulton, A. (dir.), Input, process and product : developments in teaching and language corpora. Brno : Masaryk University Press. pp. 36-53.

Gabrielatos, C. (2005). "Corpora and language teaching : just a fling or wedding bells?". Teaching English as a Second Language Electronic Journal, vol. 8, $\mathrm{n}^{\circ}$ 4. pp. 1-35. Available on line. http://teslej.org/ej32/a1.html

Jakubíček, M., Kilgarriff, A., Kovář, V., Rychlý, P. \& Suchomel, V. (2013). "The TenTen corpus family". Paper presented at the Corpus Linguistics conference. Lancaster, UK, 22-26 July 2013.

Johns, T. (1991). "Should you be persuaded : two samples of data-driven learning materials". In Johns, T. \& King, P. (dir.), Classroom concordancing. English Language Research Journal, vol. 4. pp. 1-16.

Kilgarriff, A., Rychlý, P., Smrz, P., \& Tugwell, D. (2004). "The Sketch Engine". Proceedings of EURALEX. Lorient. pp. 105-116.

McCarthy, M., McCarten, J. \& Sandiford, H. (2005). Touchstone : student book 1. Cambridge : Cambridge University Press.

Mukherjee, J. (2004). "Bridging the gap between applied corpus linguistics and the reality of English language teaching in Germany". In Connor, U. (dir.), Applied corpus linguistics : a multidimensional perspective. Amsterdam : Rodopi. pp. 239-250.

O'Keeffe, A., McCarthy, M. \& Carter, R. (2007). From corpus to classroom. Cambridge : Cambridge University Press.

Reppen, R. (2010). Using corpora in the language classroom. New York : Cambridge University Press. Rundell, M. \& Atkins, S. (2008). The Oxford guide to practical lexicography. Oxford : Oxford University Press.

Sinclair, J. (dir.). (1987). Looking up : an account of the COBUILD project in lexical computing. Londres / Glasgow : Collins ELT.

\section{NOTES}

1. See http://www.macmillandictionaries.com/features/from-corpus-to-dictionary/, Sinclair (1987) and Rundell and Atkins (2008) for information on how modern lexicography makes use of corpus data.

2. See O'Keeffe et al. (2007) for an account of how corpus data can be harnessed to produce textbooks for language learners. 
3. For example, see http://calper.la.psu.edu/corpus_portal/tutorial_overview.php, http:// www.ict4lt.org/en/en_mod3-4.htm, https://eltadvantage.ed2go.com/, and_http://corpuscall.eu/. 4. As explained in the main text, grimple is an invented word used in these concordance lines to replace a real English word.

5. Corpus of Contemporary American English, available on line at http://corpus.byu.edu/coca/. See also Davies (2008).

6. http://www.natcorp.ox.ac.uk/index.xml.

7. The enTenTen corpus is a large web-based corpus available from the Sketch Engine at https:// the.sketchengine.co.uk/. See also Kilgarriff et al. (2004) and Jakubíček et al. (2013).

8. The entire slideshow can be downloaded from http://anafrankenberg.synthasite.com/ resources/Pay\%2BPreposition.pps.

9. HotPotatoes was developed by Stewart Arneil and Martin Holmes at the University of Victoria, Canada, and can be downloaded from http://hotpot.uvic.ca/.

10. The full exercise can be downloaded from http://anafrankenberg.synthasite.com/nonmetric-units.php.

11. The last concordance line in Figure 4 is an edited version of what was originally *We got lots of congratulations from passer-bys.

12. See footnote 8 .

13. Available at http://quod.lib.umich.edu/m/micase/.

14. Available at http://www.someya-net.com/concordancer/index.html.

15. See Boulton (2010b) for a comprehensive account of such studies until 2010.

\section{ABSTRACTS}

This paper discusses how learners can come into contact with corpora and the different ways in which corpora can be useful to them. There are three main ways in which this can be done, and rather than competing against each other, I see these three different gateways to corpora as being complementary. I also wish to show that, as with any kind of materials and activities developed under the aegis of a particular methodology and approach to learning, some uses of corpora in the classroom can be very effective, while others may not work at all.

Cette contribution s'intéresse aux modalités d'entrée en contact avec des corpus chez l'apprenant et aux différentes manières qu'il a de les utiliser. Il est possible d'identifier trois approches différentes. Plutôt que de les opposer, je les considérerai comme complémentaires. Je souhaite exposer ici le fait que, comme pour toute ressource pédagogique ou pour toute activité d'apprentissage, certains usages des corpus peuvent être très efficaces dans le cours de langue alors que d'autres peuvent se révéler complètement inutile du point de vue de l'apprenant.

\section{INDEX}

Keywords: corpora, language learning, data-driven learning, computer-assisted language learning

Mots-clés: corpus, apprentissage des langues, data-driven learning, apprentissage sur corpus, apprentissage des langues assisté par ordinateur 


\section{AUTHOR}

\section{ANA FRANKENBERG-GARCIA}

Ana Frankenberg-Garcia is Senior Lecturer in Translation Studies and Programme Director of the MA in Translation at the University of Surrey. Her research focuses on applied uses of corpora in language learning, lexicography and translation. She created the COMPARA parallel corpus of English and Portuguese (www.linguateca.pt/COMPARA) and is currently working on corpusbased Portuguese-English dictionary soon to be published by Oxford.

Email: a.frankenberg-garcia@surrey.ac.uk.

Website: http://anafrankenberg.synthasite.com.

Address: University of Surrey, Faculty of Arts and Human Sciences, School of English and

Languages, Centre for Translation Studies, Guildford, Surrey, GU2 7XH, UK 